\title{
A formação judiciária na União Europeia e os solicitadores
}

Dora Resende Alves*

Márcia Costa Bento**

\section{INTRODUÇÃO}

A criação de uma cultura judiciária europeia comum a todos os EstadosMembros pressupõe que todos os profissionais de justiça, como é o caso dos solicitadores, possam participar de uma formação adequada de direito da União Europeia ${ }^{1}$.

As universidades, como instituições académicas, têm reconhecidamente um papel ativo neste objetivo, mas será suficiente?

Pois que, para a criação de um espaço comum de liberdade, segurança e justiça é necessário desenvolver a formação judiciária de uma forma contínua, isto é, após a frequência nas universidades, durante o exercício das profissões forenses.

A questão que preside este trabalho centra-se numa "preocupação" sobre a necessidade de formação a nível de direito da União, apesar de existir um discurso europeu de incentivo e inclusão. Contudo, na verdade, a perceção nacional, não é exatamente a mesma.

Ora, a aplicação incorreta de normas de direito da União Europeia coloca em causa a aplicação uniforme desse direito e, em consequência, os direitos dos cidadãos europeus.

No que nos ocupa hoje, ao solicitador, como profissional forense, para além das suas normas nacionais, é "exigido", pela própria estrutura descentralizada da

\footnotetext{
* Doutora em Direito. Professora Auxiliar da Universidade Portucalense Infante D. Henrique e Investigadora do Instituto Jurídico Portucalense, Portugal.

** Mestre em Direito pela Universidade Portucalense Infante D. Henrique, doutoranda pela Universidade de Vigo, Espanha, e Investigadora do Instituto Jurídico da Universidade Portucalense Infante D. Henrique, Portugal.
} 
União Europeia um bom conhecimento de legislação, doutrina e jurisprudência comunitárias.

\section{A FORMAÇÃO JUDICIÁRIA NA PERSPETIVA DA UNIÃO EUROPEIA}

Considera a Comissão que o "impacto da legislação da UE no dia-adia dos cidadãos e das empresas da UE é de tal modo importante que qualquer profissional do direito nacional - desde os advogados e oficiais de justiça até aos juízes e procuradores - deve ter também sólidos conhecimentos do direito da UE e poder interpretá-lo e aplicá-lo eficazmente, paralelamente ao direito nacional. Num sistema jurídico descentralizado como o da União, os juízes nacionais devem muitas vezes tornar-se "juízes de direito da União” para poderem assumir as suas responsabilidades. A formação dos profissionais do direito da UE é, por conseguinte, de primordial importância para garantir a correta aplicação do direito da UE, instaurar um clima de confiança mútua nos sistemas judiciais e permitir a cooperação e a confiança entre profissionais além-fronteiras."

Assim, a União Europeia fornece até apoio financeiro para a formação judiciária que reconhece como um desafio fundamental na criação do espaço judiciário europeu, embora deixe a organização dessa formação sobretudo na responsabilidade dos Estados-Membros a quem cabe integrar plenamente a dimensão europeia ${ }^{3}$. Os sistemas jurídicos e judiciários dos Estados-Membros apresentam uma grande diversidade e para a criação de uma cultura judiciária europeia comum é essencial que todos os profissionais de justiça: juízes, procuradores, funcionários, agentes de justiça, advogados e solicitadores possam participar de uma formação adequada no domínio do direito europeu ${ }^{4}$. As universidades, como instituições académicas, têm, reconhecidamente, um papel ativo neste objetivo ${ }^{5}$.

O Tratado de Funcionamento da União Europeia (TFUE) associou a criação de um espaço de liberdade, segurança e justiça e a salvaguarda dos direitos fundamentais e a ordem jurídica da União Europeia e respetivos EstadosMembros $^{6}$. Por regulamento ${ }^{7}$ estabeleceu-se um quadro geral comunitário de atividades para facilitar a cooperação judiciária em matéria civil. As atividades comunitárias neste domínio englobam ações de apoio à organização incentivando e promovendo a cooperação judiciária em matéria civil ${ }^{8}$, bem como ações de apoio a projetos específicos ${ }^{9}$.

Para a criação do espaço de liberdade, segurança e justiça, torna-se necessário desenvolver em permanência a formação judiciária ${ }^{10}$, como instrumento auxiliar, em particular para melhorar os conhecimentos dos profissionais sobre os instrumentos jurídicos da União Europeia, com compreensão mútua dos sistemas jurídicos dos Estados-Membros e formação em matéria de línguas ${ }^{11}$. 
Embora seja tarefa dos Estados-Membros integrarem plenamente a dimensão europeia nas suas atividades nacionais, admitiu-se desenvolver um nível mais integrado de formação, concebido e aplicado a nível europeu. Criam-se formas de proporcionar a todos os juízes ${ }^{12}$, procuradores, funcionários e agentes de justiça um conhecimento suficiente dos instrumentos de cooperação judiciária europeia para que recorram plenamente ao direito primário e derivado da União Europeia, bem como conheçam a legislação e os sistemas jurídicos dos outros Estados-Membros ${ }^{13}$.

Pretende-se que todos os profissionais de justiça contribuam para um espaço de justiça comum. Os advogados e solicitadores não são excluídos, mas pretende-se que sejam as respetivas ordens profissionais a desenvolver as ações de formação adequada, sem que as instituições europeias e estaduais exerçam diretamente essa tarefa.

Nesse sentido, desde, pelo menos, 2006, a União Europeia tem demonstrado a sua preocupação crescente quanto à formação judiciária. Pelo que, nesse ano, Comissão Europeia apresentou ao Parlamento e ao Conselho uma Comunicação sobre a formação judiciária na União Europeia ${ }^{14}$.

Pouco depois, foiadotada uma Resolução do Conselhoe dos Representantes dos Governos dos Estados-Membros reunidos no Conselho relativa à formação dos juízes, procuradores e funcionários ao serviço da administração da justiça na União Europeia ${ }^{15}$.

E em seguida, o Parlamento Europeu publicou um estudo sobre o reforço da formação judiciária na União Europeia ${ }^{16}$.

A entrada em vigor do Tratado de Lisboa, em dezembro de $2009^{17}$, proporcionou uma base jurídica para as atividades relacionadas com a formação judiciária europeia. Os artigos $81.0^{\circ}$ e $82 .{ }^{\circ}$ do TFUE $^{18}$ prevêem "o apoio à formação dos magistrados e dos funcionários e agentes de justiça" como uma das medidas necessárias para reforçar a cooperação judiciária em matéria civil, comercial e penal.

Foi, também, em dezembro de 2009, que o Conselho com o Programa de Estocolmo ${ }^{19}$ veio, entre outros importantes reptos na dimensão da cooperação judiciária, dar grande destaque à questão da formação judiciária europeia para todos os profissionais do direito.

No âmbito do Plano de Ação do Programa de Estocolmo e do Relatório de $2010^{20}$ sobre a cidadania da União, a Comissão definiu a formação judiciária europeia como uma prioridade. Também o Parlamento Europeu tem sublinhado reiteradamente que uma formação judiciária adequada constitui um contributo significativo para a melhoria do funcionamento do mercado interno, tornando mais fácil para os cidadãos o exercício dos seus direitos. 
As principais recomendações do relatório do Professor Mario Monti intitulado Uma nova estratégia para o Mercado Único ${ }^{21}$, incluem a intensificação da formação dos juízes e profissionais da justiça em direito da União Europeia.

No final de 2010, a Comissão lançou uma consulta das partes interessadas, incluindo os Estados-Membros, os membros do Fórum da Justiça e as redes e estruturas europeias de formação e os seus membros, no sentido de recolher informações e, em 2011, a Comissão Europeia aprovou a Comunicação Confiança numa justiça à escala da UE - uma nova dimensão para a formação judiciária europeia ${ }^{22}$.

Também o Conselho da Justiça e dos Assuntos Internos, nas suas conclusões, de 27 e 28 de outubro de 2011, sobre formação judiciária europeia, incentivou a partilha anual de informações com a Comissão sobre a formação disponível em direito da União Europeia e o número de profissionais formados, tendo convidado a Comissão a analisar a possibilidade de apresentar um relatório anual sobre a formação judiciária europeia.

Ainda, em 2012, o Parlamento Europeu propôs o lançamento de um projeto-piloto sobre a formação judiciária europeia, com vista a contribuir para: identificar as melhores práticas na formação de juízes, procuradores e profissionais da justiça sobre as tradições e os sistemas jurídicos nacionais, assim como sobre o direito da União; identificar as formas mais eficazes de ministrar formação sobre o direito da UE e os sistemas jurídicos nacionais a juízes, procuradores e profissionais da justiça a nível local, bem como promover o diálogo e a coordenação entre juízes e procuradores da União Europeia; incentivar os organismos de formação judiciária da União Europeia a partilharem ideias sobre as melhores práticas e a divulgá-las na UE; e melhorar a cooperação entre a Rede Europeia de Formação Judiciária (REFJ) e as instituições nacionais de formação judiciária. Tal envolverá organismos de formação, tais como a Academia de Direito Europeu ${ }^{23}$, e as organizações profissionais a nível europeu como a Rede Europeia dos Conselhos de Justiça ${ }^{24}$, a Rede de Presidentes dos Supremos Tribunais ${ }^{25}$, a Associação dos Conselhos de Estado e dos Supremos Tribunais Administrativos ${ }^{26}$ e a Rede dos Procuradores-Gerais dos Supremos Tribunais de Justiça da UE ${ }^{27}$.

Neste âmbito, a título de exemplo, em abril de 2013, que a Comissão Europeia organizou uma conferência para promover a formação judiciária europeia ${ }^{28}$.

A então Vice-Presidente Viviane Reding proferiu um discurso na sessão de trabalho do Parlamento Europeu sobre a formação jurídica: um instrumento essencial para a excelência judiciária europeia ${ }^{29}$, onde defendeu que o impacto da legislação europeia sobre a vida quotidiana dos cidadãos, dos consumidores europeus, dos trabalhadores, das empresas e sobre as estruturas políticas ejurídicas nacionais é profunda. Apontando, também, três razões para demonstrar que a formação dos profissionais da justiça em direito da União Europeia é essencial. Em primeiro lugar, a formação jurídica e judicial de direito da União Europeia 
garante a confiança mútua entre aqueles cujo trabalho é aplicar a legislação comunitária. Em segundo lugar, a formação jurídica e judiciária torna mais fácil a cooperação transfronteiriça. E em terceiro lugar, proporciona maior segurança e certeza jurídicas em toda a União Europeia, para os cidadãos e as empresas.

Lançado o desafio para uma breve abordagem sobre o tema do estatuto e da formação dos solicitadores ${ }^{30}$, cumpre-nos salientar a importância do conhecimento do direito comunitário, pois que, como se referiu anteriormente, cada vez mais, o direito da União está presente, porque se aplica no dia-a-dia dos cidadãos e das empresas da União Europeia, e é necessário que qualquer profissional de direito nacional, como o caso dos solicitadores, tenham sólidos conhecimentos do mesmo.

\section{FONTES DE DIREITO DA UNIÃO: BREVE SÍNTESE}

O direito da União Europeia é um direito novo, com menos de 70 anos $^{31}$, como podemos analisar através das suas fontes, designadamente pelos dos Tratados que criaram as Comunidades Europeias, resultando, assim, uma nova ordem jurídica com uma finalidade própria e independente da dos EstadosMembros, mas com que esta se relaciona, numa dupla origem convencional e unilateral $^{32}$.

Assim sendo, antes de avançarmos para a análise do Estatuto e Formação dos Solicitadores, tendo em conta a importância do direito da União Europeia no quotidiano destes profissionais judiciais, de seguida, iremos resumidamente aflorar as fontes do referido direito.

Importa saber como e onde nasce o direito objetivo ${ }^{33}$ (direito como sistema organizado de princípios e normas que se destinam aos membros de uma comunidade, visando a realização das suas finalidades comuns), como se forma e se revela aos particulares. Surge a expressão fontes de direito - sugestiva, que nos dá desde logo a ideia de lugares onde nasce ou se forma o direito objetivo.

Mas a expressão não é usada pelos autores sempre num mesmo sentido ${ }^{34}$. É uma expressão que traduz diversos significados. Assim temos, os mais usuais: fontes de direito em sentido sociológico, causal ou genético; fontes de direito em sentido material ou instrumental; fontes de direito em sentido político ou orgânico; e, o que mais nos importa, fontes de direito em sentido técnico-jurídico, formal ou de juridicidade, como os modos de formação e revelação do direito objetivo, saber de que modo se constitui e se manifesta o direito positivamente vigente numa determinada comunidade histórica, ou seja, de que modo o direito se objetiva aí como direito, fundamental e tradicionalmente reduzidos em cada sociedade onde teremos que analisar a importância de cada uma delas ${ }^{35}$ : lei, costume, jurisprudência e doutrina. 
A ordem jurídica a que as organizações internacionais estão sujeitas é constituída pelas regras do direito internacional comum ou geral aplicáveis, pelas regras de direito internacional particular estabelecidas no respetivo pacto constitutivo e que constituem o seu direito originário, primário ou fundamental e ainda pelas disposições dos atos unilaterais adotados no seio dessa organização internacional pelos órgãos competentes, que constituem o seu direito derivado ou secundário uma vez que, criado na conformidade e segundo os procedimentos prescritos no ato fundador, dele derivam ${ }^{36}$.

\subsection{Fontes Escritas}

\section{a) Direito originário da União Europeia}

O direito originário da União Europeia ou primário é, segundo um critério de fonte formal, o direito criado pelos Estados-Membros através de tratados internacionais, constituído pelas normas que criaram as Comunidades Europeias e a União Europeia, conferindo-lhes as suas atribuições e regulando a sua organização e funcionamento internos, bem como as alterações a estes tratados. Trata-se do direito que criou e moldou a atual União Europeia, expresso nas normas de diversos tratados internacionais ${ }^{37}$.

Portanto, o direito originário ou primário da União Europeia tende a seguir um critério formal, como o direito criado pelos Estados-Membros através de tratados internacionais, constituído pelas normas que criaram a União Europeia, conferindo-lhe as suas atribuições e regulando a sua organização e funcionamento internos, bem como aquelas normas que vêm modificando e completando o sentido dos tratados originários.

Assim, aqui se incluem: os tratados que instituíram as Comunidades e a União Europeia ${ }^{38}$; os tratados de revisão ${ }^{39}$; os tratados de adesãa ${ }^{40}$; outros tratados que alteraram disposições originárias ${ }^{41} \mathrm{e}$ atos de valor idêntico.

\section{b) Direito derivado da União Europeia}

Por sua vez, o direito derivado ou secundário na União Europeia é o direito que resulta dos tratados institutivos, baseia-se nos tratados e implica uma série de procedimentos aí previstos. É constituído pelos atos adotados pelos órgãos União Europeia, no desempenho das competências que os tratados lhes conferem, podendo assumir as formas típicas previstas no artigo $288 .^{\circ}$ do $\mathrm{TFUE}^{42}$.

\subsubsection{Classificação das fontes de direito da União: obrigatórias ou não obrigatórias}

\section{a) Fontes obrigatórias}

As fontes de direito da União são classificadas como obrigatórias ou não obrigatórias. Como fontes obrigatórias de direito comunitário existem os 
regulamentos (são atos diretamente aplicáveis e obrigatórios em todos os EstadosMembros sem que seja necessária qualquer legislação de aplicação. Podem resultar do Conselho ${ }^{43}$, da Comissão ${ }^{44}$, do Conselho, do Parlamento Europeu ${ }^{45}$, muitas vezes nos termos do processo legislativo ordinário do artigo $294 .^{\circ}$ do TFUE, e ainda do Banco Central Europeu $\left.{ }^{46}\right)^{47}$; diretivas ${ }^{48}$ (vinculam os Estados-Membros quanto aos objetivos a alcançar num determinado prazo, deixando, no entanto, às instâncias nacionais a competência quanto à forma e aos meios a utilizar. Têm de ser transpostas para o direito interno de cada país de acordo com os seus procedimentos específicos. Podem resultar do Conselho, da Comissão ou ainda do Conselho e do Parlamento Europeu, também nos termos do processo legislativo ordinário. No caso português, deve ser transpostas através de ato legislativo: lei, decreto-lei ou decreto legislativo regional, nos termos do artigo $112 .^{\circ}, \mathrm{n} .^{\circ} 8$, da CRP); decisões ${ }^{49}$ (são vinculativas na sua integralidade para os seus destinatários, não requerem legislação de transposição nacional; pode ter destinatários certos e pode ser dirigida a um ou a todos os Estados-Membros, bem como a empresas e pessoas singulares $)^{50}$.

\section{b) Fontes não obrigatórias}

Quanto às fontes não obrigatórias de direito comunitário, existem as recomendações e os pareceres, não são atos vinculativos ${ }^{51}$, apenas, constituem um convite aos seus destinatários (podem ser outra instituição, os Estados-Membros e até particulares), para que adotem determinada regra de conduta, com um significado político e psicológico, na medida em que poderão produzir efeitos indiretos, de acordo com o previsto no artigo $288 .^{\circ}, \S 5 .^{\circ}$, do TFUE.

As recomendações aconselham a adoção de determinado comportamento relativamente a certas matérias concretas. Trata-se de um instrumento de ação indireta com o fim de harmonizar as legislações. Apenas, se distingue da diretiva pela ausência de obrigatoriedade. Podem ser emitidas pelo Conselho ${ }^{52}$ ou pela Comissão $^{53}$, mas é possível encontrar exemplos de recomendações de outras instituições ${ }^{54}$.

Os pareceres traduzem a opinião de uma instituição comunitária sobre qualquer matéria concreta ${ }^{55}$. Também aqui é possível encontrar pareceres oriundos das diversas instituições ${ }^{56}$.

\subsubsection{Atos sui generis ou atos atípicos}

Para além do supra referido, existem também os atos sui generis ou atos atípicos $^{57}$ que são atos adotados pelas instituições comunitárias uns previstos por artigos dos tratados e outros ainda que não previstos expressamente pelos tratados (atípicos porque não previstos no artigo $288 .^{\circ}$ do $\mathrm{TFUE}^{58}$ ), antes nascem da prática comunitária ${ }^{59}$. Estes atos não estão, por regra ${ }^{60}$, sujeitos ao controlo do Tribunal de Justiça da União Europeia e podem, em certos casos, ultrapassar as competências dos tratados. Podem ser: regulamentos internos ${ }^{61}$ ou financeiros ${ }^{62}$, 
previstos em certas disposições dos Tratados ${ }^{63}$; atos preparatórios inseridos no processo comunitário de decisão ${ }^{64}$ como propostas $^{65}$ ou projetos e mesmo algumas diretivas; decisões de variada origem e características ${ }^{66}$; comunicações $^{67}$; conclusões; programas de ação ou linhas orientadoras ${ }^{68}$; recomendações $^{69}$; códigos de conduta $^{70}$; livros verdes ${ }^{71}$; livros brancos ${ }^{72}$; relatórios $^{73}$; instruções ${ }^{74}$; acordos interinstitucionais ${ }^{75}$; posições comuns ${ }^{76}$; cartas administrativas de arquivamento de processos (comfort letters) ${ }^{77}$.

Acrescem ainda numerosos documentos tornados públicos ou sujeitos a registo por cada uma das instituições ${ }^{78}$ sob o título Actos aprovados ao abrigo dos Tratados CE/Euratom cuja publicação não é obrigatória no Jornal Oficial da União Europeia: documentos $\mathrm{COM}^{79}$ da Comissão, documentos SEC, a publicação de orçamentos $^{80}$, informações ${ }^{81}$ sob o título Informações oriundas das instituições e dos órgãos da União Europeia. Ainda, procedimentos administrativos como convite de uma instituição ${ }^{82}$ sob o título Avisos.

\subsubsection{Direito complementar dos Tratados}

Constituem direito complementar dos Tratados as convenções concluídas pelos Estados-Membros em execução do anterior artigo 293. ${ }^{\circ}$ do $\mathrm{TCE}^{83}$, tais como: convenções não previstas pelos Tratados e celebradas entre os EstadosMembros e as decisões dos representantes dos Estados-Membros reunidos no seio do Conselho (são textos adotados nas reuniões do Conselho mas com o valor de conferência diplomática. Os representantes dos Estados-Membros despem a sua veste comunitária para se transformarem em simples representantes nacionais, aproveitando o apoio burocrático do Conselho e decidindo matérias que não são da competência do mesmo, mas interessam à integração europeia ${ }^{84}$ ).

\subsubsection{Fontes Externas}

Por fim, quanto às fontes externas, está em causa o relacionamento entre os tratados e os demais compromissos internacionais assumidos pelos EstadosMembros $^{85}$, assim como a capacidade para a União Europeia concluir acordos internacionais ${ }^{86}$.

Podem consistir em: acordos concluídos pela União Europeia com terceiros Estados ou organizações internacionais (na medida em que foi conferida personalidade jurídica internacional à União Europeia no artigo 47..$^{\circ}$ do TUE, pelas alterações do Tratado de Lisboa ${ }^{87}$, o que lhe permite agir autonomamente, em seu próprio nome, quer na ordem interna, quer na ordem internacional ${ }^{88}$. $\mathrm{E}$ o artigo 3. ${ }^{\circ}, \mathrm{n},{ }^{\circ}$ 2, do TFUE refere a competência exclusiva da União Europeia para celebrar acordos internacionais quando: tal celebração esteja prevista num ato legislativo da União; seja necessária para lhe dar a possibilidade de exercer a 
sua competência interna; ou seja suscetível de afetar regras comuns ou de alterar o alcance das mesmas.

No caso da UE, os acordos internacionais vinculam diretamente a União e as suas instituições, sem necessidade de transposição legislativa interna (artigo $216 .^{\circ}$, n. $^{\circ}$ 2, do TFUE). Os acordos internacionais são fonte direta de direito da União e, portanto, fonte direta de obrigações (e de direitos) internacionais ${ }^{89}$. De resto, da mesma forma, elas vinculam também os Estado-Membros, sem necessidade de ratificação interna ou de transposição legislativa interna, visto que incumbe aos Estados-Membros aplicar em geral o direito da União na sua ordem interna (artigo 291. ${ }^{\circ}$, n. $^{\circ} 1$, do TFUE) $)^{90}$.

Tratados concluídos pelos Estados-Membros com terceiros Estados ou organizações internacionais (de acordo com o artigo $207 .^{\circ}$, n. ${ }^{\circ} 5$, e $218 .^{\circ}$ do TFUE) e tratados concluídos pelos Estados-Membros entre si (nomeadamente, tratados internacionais celebrados entre todos ou alguns dos Estados-Membros da União Europeia, mas à margem dos Tratados constitutivos ${ }^{91}$ ).

\subsubsection{Fontes não escritas}

Por fim, importa referir que o direito da União Europeia, também decorre de fontes não escritas ${ }^{92}$, nomeadamente dos princípios gerais comuns aos direitos dos Estados-Membros, dos princípios gerais de direito comuns às nações civilizadas, dos princípios gerais de direito internacional ou dos princípios gerais de direito da União Europeia.

Menção mais detalhada merece a jurisprudência do Tribunal de Justiça da União Europeia. A jurisprudência comunitária ${ }^{93}$ surge no quadro das fontes de direito da União Europeia com um papel de relevo, não tanto pela sua obrigatoriedade, mas pelo papel preponderante que assume na construção da integração comunitária. A evolução comunitária tem-se alcançado através da cooperação dos Estados-Membros na aplicação do direito comunitário e a jurisprudência comunitária tem permitido a concretização desse direito, não só pela sua função jurisdicional própria, mas acima de tudo como fonte de uniformização desse direito. Aliás, o meio próprio para a resolução de dúvidas na interpretação do direito comunitário reside exatamente na competência exclusiva do Tribunal de Justiça para o interpretar, quando os órgãos jurisdicionais nacionais ${ }^{94}$, na sua tarefa de aplicação ordinária do direito comunitário, se deparam com dificuldades. Assim, surge o chamado reenvio prejudicial ${ }^{95}$, uma ação da competência exclusiva do Tribunal de Justiça da União Europeia prevista no artigo 267. ${ }^{\circ}$ do TFUE. A jurisprudência inclui os numerosos acórdãos ${ }^{96}$ dos tribunais comunitários que resultam de três instâncias (veja-se o artigo $19 .{ }^{\circ}$ do TUE): Tribunal de Justiça da União Europeia (nova denominação com o Tratado de Lisboa, era denominado Tribunal de Justiça das Comunidades Europeias no TCE) ${ }^{97}$, Tribunal Geral (nova denominação com o Tratado de Lisboa, artigo 2. ${ }^{\circ}$, A. 2), alínea n), para o antes 
Tribunal de Primeira Instância das Comunidades Europeias no TCE $)^{98}$ e aquele que foi o Tribunal da Função Pública da União Europeia, único tribunal especializado entre 2005 e $2016^{99}$. Desde os Tratados institutivos (1951 e 1957) que o direito da União Europeia utiliza conceitos próprios e adaptáveis a uma multiplicidade de conteúdos, porque se trata de um direito aplicável a um número crescente de Estados-Membros. Conceitos, pela sua própria natureza e intenção, incompletos ou, pelo menos, abertos a um conteúdo a construir. É nessa construção que o Tribunal de Justiça da União Europeia, bem como o Tribunal Geral desde 1988 têm representado um papel inestimável de preenchimento e explicitação dos conceitos. Num tempo ainda recente, e já findo, uma outra jurisdição contribuiu também para o acervo, o Tribunal da Função Pública da União Europeia ${ }^{100}$. O Tribunal de Justiça tem privilegiado, na sua interpretação, o método sistemático e teleológico, isto é, tendo em conta as finalidades dos Tratados e o efeito útil das diretivas e, assim, com a sua jurisprudência, tem criado muitos princípios hoje referenciados como fundamentais na ordem jurídica comunitária e muitos já hoje consagrados nos Tratados. Também, em especial, desempenha um papel de relevo na interpretação das liberdades de circulação, formas básicas de funcionamento do já conseguido mercado interno, ao interpretar restritivamente as disposições que restringem as liberdades comunitárias e extensivamente as que as ampliam.

Podemos ainda mencionar o costume. Porém, a doutrina não é unânime ao considerar o costume como fonte de direito da União Europeia ${ }^{101}$.

\section{O SOLICITADOR NA UNIÃO EUROPEIA}

\subsection{0 estatuto de solicitador}

Uma específica profissão jurídica surge mencionada na história de Portugal desde 1174 com o nome "vozeiro", figura que era indistinta nas funções de Solicitador e Advogado. Surge depois em 1241 com a denominação de "procuradores". Em 1446, na menor idade de D. Afonso V e sob a regência do infante D. Pedro, foram publicadas as Ordenações Afonsinas, primeiro corpo de leis organizado e, aí, a distinção das funções. Em 1468, já identificado o cargo de solicitador ${ }^{102}$.

O solicitador é hoje uma profissão jurídica reconhecida pela União Europeia, se bem que não exista com esse nome e funções em todos os países membros. Trata-se, por norma, de um profissional liberal que exerce a sua atividade tendo em conta os limites impostos pelo seu estatuto legal.

Em Portugal ${ }^{103}$, reconhece-a o Estatuto da Ordem dos Solicitadores e dos Agentes de Execução, pela Lei n. $^{\mathbf{0}} \mathbf{1 5 4 / 2 0 1 5}$, de 14 de setembro ${ }^{104}$ e outras disposições legais pontuais, a propósito de atribuições específicas.

A nível europeu, a atividade de solicitadoria é regulada pela Carta Deontológica dos Postulantes Europeus ${ }^{105}$, curiosamente aprovada em congresso 
levado a cabo por solicitadores portugueses, procuradores espanhóis e os huissiers franceses, em Cádis, Espanha, em novembro de 2000, e ratificada, à época, pela Assembleia Geral da Câmara dos Solicitadores portuguesa em 13 de outubro de 2001.

A referida Carta tem como objetivo geral reforçar a relevância das profissões forenses como garante da proteção dos direitos humanos ${ }^{106}$.

Para além do documento supra referido, os solicitadores são também representados a nível europeu pela Union Internationale des Huissiers de Justice $(U I H J)^{107}$, com o objetivo de representação em organizações internacionais e que, também, pretende promover a colaboração entre organismos profissionais nacionais. Estabelece que o solicitador "trabalha em prol da melhoria do direito processual nacional e dos tratados internacionais e envida esforços para promover ideias, projetos e iniciativas que contribuam para a evolução desta profissão e a elevação do estatuto dos seus membros".

As principais funções de um solicitador ${ }^{108}$ consistem, então, no exercício do mandato forense (mandato judicial conferido para ser exercido em qualquer tribunal, incluindo os tribunais ou comissões arbitrais e os julgados de paz); a consulta jurídica (atividade de aconselhamento jurídico que consiste na interpretação e aplicação de normas jurídicas mediante solicitação de terceiro); a elaboração de contratos e a prática dos atos preparatórios tendentes à constituição, ação ou extinção de negócios jurídicos, designadamente os praticados junto de conservatórias e cartórios notariais; a negociação tendente à cobrança de créditos e o exercício do mandato no âmbito de reclamação ou impugnação de atos administrativos ou tributários.

Os solicitadores exercem a consulta jurídica e o mandato forense dentro dos limites impostos pelo seu estatuto e pela legislação processual, podendo representar as partes sempre que não seja obrigatória a constituição de advogado, como é o caso do Código de Processo Civil português, artigos 42. ${ }^{\circ}$ e 52. ${ }^{\circ 109}$.

Para aceder e exercer a profissão é necessário que o interessado cumpra com determinados requisitos e que se inscreva na Ordem dos Solicitadores.

A Ordem dos Solicitadores é representativa dos mesmos. Compete-lhe, nomeadamente, exercer o poder disciplinar sobre os seus membros e emitir parecer sobre projetos de diplomas legislativos relacionados com as suas atribuições.

\subsection{A formação do solicitador}

Um solicitador no exercício das suas funções pode, dado momento, ser confrontado com normas de direito União Europeia. Perante esta realidade, questiona-se até que ponto existe formação e um bom conhecimento das normas de direito da União? 
A formação do solicitador é indispensável à salvaguarda da proteção dos direitos dos cidadãos, isto é, como profissional forense, tem como objetivo acautelar os interesses dos seus clientes.

Uma das áreas mais importantes, no que toca à formação, mas muitas vezes, esquecida é a do direito comunitário e, isto porque, desde logo, porque os tribunais nacionais funcionam como tribunais comuns de aplicação de direito da União, na medida em que este, por vezes, é dotado de efeito direto ${ }^{110} \mathrm{em}$ muitas das suas normas e atento o princípio da tutela jurisdicional efetiva ${ }^{111}$. Por conseguinte, a correta aplicação do direito comunitário depende muito dos sistemas judiciários nacionais, pelo que o seu conhecimento, pelos diversos operadores judiciários, como os solicitadores, é essencial para a correta aplicação da legislação da União Europeia ${ }^{112}$. Sendo assim, necessário, uma formação judiciária contínua.

Num momento em que se prefigura, como desafio fundamental na União Europeia, a concretização de um espaço judiciário europeu, dada a diversidade de sistemas jurídicos e judiciários no território europeu, criação essa que, como deflui do sobredito, reclama sobretudo formação judiciária ${ }^{113}$ adequada, deixa-se, porém, a cada Estado-Membro a organização dessa formação, na grande parte dos casos.

O reconhecimento deste pilar fundamental na construção do espaço comum europeu consubstanciou-se, além do mais, na emissão de regulamento comunitário já mencionado ${ }^{114}$ e no qual se estabeleceu um quadro geral comunitário de atividades para facilitar a cooperação judiciária em matéria civil, bem como se têm dado passos gigantescos em matéria de criação de um espaço comum de liberdade, segurança e justiça.

Posto isto, o que concluir perante a realidade nacional?

Existe um discurso europeu de inclusão e incentivo à formação dos profissionais forenses, contudo não é, exatamente, a mesma perceção a nível nacional. Pelo que, será ainda necessário conciliar as duas visões, necessitando de trabalho político e social para se harmonizarem.

\section{CONCLUSÃO}

As questões abordadas no presente estudo, permitem apontar algumas ideias a ter em conta, na necessária reflexão sobre o futuro do direito da União Europeia, tendo em conta a insuficiência de formação judiciária aos profissionais judiciais nessa área.

Conforme foi referido anteriormente, o impacto da legislação da União Europeia no dia-a-dia dos cidadãos e das empresas é já de tal forma frequente e importante, que é necessário para qualquer profissional de direito nacional deter, conhecimentos dessa área, de forma a poder interpretá-la e aplica-la eficazmente. 
Aliás, cada vez mais se assiste a uma crescente europeização de diversos ramos de direito, pelo que, para além dos conhecimentos básicos do direito da União Europeia, é já aconselhável ler o Jornal Oficial da União Europeia, conhecer legislação, jurisprudência e doutrina da União. Conclui-se, assim, que ao Solicitador, como profissional forense reconhecido pela União Europeia, para além dos conhecimentos de direito nacional, cada vez mais serão necessários sólidos conhecimentos do direito da União Europeia.

\section{NOTAS}

1 Ver BORCHARDT, Klaus-Dieter. ABC do Direito Comunitário. Comissão Europeia. 2017.

2 Comunicação da Comissão ao Parlamento Europeu, ao Conselho, ao Comité Económico e Social Europeu e ao Comité das Regiões sobre como conseguir uma Europa aberta e segura, de 11.03.2014, documento COM (2014) 144 final, p. 7.

3 Comunicação da Comissão ao Conselho e ao Parlamento Europeu, sobre a política de coesão e as cidades: contribuição das cidades e das aglomerações para o crescimento e o emprego nas regiões, de 13.07.2006, documento COM (2006) 356 final, pp. 9, 7, 3.

4 Resolução do Conselho e dos Representantes dos Governos dos Estados-Membros, reunidos no Conselho relativa à formação dos juízes, procuradores e funcionários e agentes de justiça na União Europeia, de 22.11.2008, documento (2008/C299/01). E mais ainda, todos os profissionais associados à atividade judiciária se entendem incluídos: solicitadores de execução, agentes de acompanhamento de liberdade condicional, mediadores e intérpretes judiciais, segundo o Regulamento (UE) N. ${ }^{\circ}$ 1382/2013 do Parlamento Europeu e do Conselho de 17 de dezembro de 2013, que cria o Programa "Justiça" para o período de 2014 a 2020, JOUE L 354 de 28.12.2013, p. 73, \$ 5.

5 Ver o Regulamento (UE) n. ${ }^{\circ}$ 1382/2013, JOUE L 354 de 28.12.2013, p. 73, § 6, e Comunicação da Comissão ao Parlamento Europeu, ao Conselho, ao Comité Económico e Social Europeu e ao Comité das Regiões sobre Gerar confiança numa justiça à escala da UE - uma nova dimensão para a formação judiciária europeia de 13.09.2011, documento COM (2011) 551 final, p. 10.

6 Resolução do Parlamento Europeu 2010/C 212 E/08, de 7 de Maio de 2009, sobre as novas competências e responsabilidades do Parlamento na aplicação do Tratado de Lisboa, JOUE C 212 E de 05.08.2010, pp. 37 a 46 (ver considerandos 4 e 23).

7 Regulamento (CE) n. ${ }^{\circ}$ 743/2002 do Conselho de 25 de Abril de 2002, que cria um quadro geral comunitário de atividades para facilitar a cooperação judiciária em matéria civil, JOCE L 115 de 01.05.2002, pp. 1 a 5 .

8 Relatório da Comissão ao Parlamento Europeu e ao Conselho, de 9 de Fevereiro de 2005, sobre a realização do relatório intercalar sobre o programa-quadro de cooperação judiciária em matéria civil (2002-2006), SEC (2005), COM (2005) 34 final de 09.02.2005.

9 Decisão n. ${ }^{\circ}$ 1149/2007/CE do Parlamento Europeu e do Conselho, de 25 de Setembro de 2007, que cria, para o período de 2007 a 201, o programa específico "Justiça Civil" no âmbito do Programa Geral "Direitos Fundamentais e Justiça" JOUE L 257 de 03.10.2007, pp. 16 a 22.

10 Comunicação da Comissão Europeia ao Parlamento e ao Conselho sobre a formação judiciária na União Europeia de 29.06.2006, documento COM (2006) 356 final.

11 Resolução do Parlamento Europeu 2013/C 251 E/07 de 14 de março de 2012, sobre formação judiciária, nos termos dos artigos $81 .^{\circ}$ e 82. ${ }^{\circ}$ do TFUE (2012/2575 (RSP)), JOUE C 251 de 31.08.2013, Considerando 3., p. 44.

A preocupação permanece, conforme a. Recomendação do Conselho 2019/C 189/03 de 22 de maio de 2019 relativa a uma abordagem global do ensino e aprendizagem das línguas, no JOUE C 189 de 
05.06.2019, pp. 15 a 22. Ver, no tema, ALVES, Dora Resende e AGUIAR, Ana Raquel. “A diversidade linguística na União Europeia”, 2018.

12 Como um exemplo, ver JOUE C 45 de 16.02.2013, p. 2.

13 A Rede Europeia de Formação Judiciária (REFJ), acessível em http://www.ejtn.eu/fr/, associação fundada em Outubro de 2000, já vinha exercendo essa função.

14 Comunicação da Comissão ao Parlamento Europeu e ao Conselho, sobre a formação judiciária na União Europeia de 29.06.2006, documento COM/2006/0356.

15 Resolução do Conselho e dos Representantes dos Governos dos Estados-Membros, reunidos no Conselho, 2008/C 299/01, de 22 de Novembro de 2008, relativa à formação dos juízes, procuradores e funcionários e agentes de justiça na União Europeia, JOUE C 299/1 de 22.11.2008.

16 Renforcement de la Formation Judiciaire Dans Lunion Européenne - Libertés Civiles, Justice et Affaires Intérieures, de abril de 2009, PE 419.591.

17 ALVES, Dora Resende. “Notas sobre o Tratado de Lisboa de 13 de Dezembro de 2007”. 2008.

18 Os tratados da União Europeia em GORJÃO-HENRIQUES, Miguel. Tratado de Lisboa. 2018.

19 Programa de Estocolmo - Uma Europa aberta e segura que sirva e proteja os cidadãos, 2010/C 115/01 no JOUE C 115 de 04.05.2010, pp. 1 a 38.

20 Relatório da Comissão Europeia, de 27 de Outubro de 2010, sobre a Cidadania da União, eliminar os obstáculos ao exercício dos direitos dos cidadãos da UE, documento COM (2010) 603 final.

21 Relatório de Mario Monti, de 9 de Maio de 2010, intitulado "Uma nova estratégia para o Mercado Único", (2015/2354(INI)).

22 Comunicação da Comissão ao Parlamento Europeu, ao Conselho, ao Comité Económico e Social Europeu e ao Comité das Regiões sobre gerar confiança numa justiça à escala da UE - uma nova dimensão para a formação judiciária europeia de 13.09.2011, documento COM (2011) 551 final.

23 Acessível em: https://www.era.int/cgi-bin/cms?_SID=NEW\&_sprache=en\&_bereich=ansicht\&_ aktion=detail\&schluessel=era.

24 Disponível em: http://www.encj.eu/.

25 Disponível em: http://network-presidents.eu/.

26 Acessível em: http://www.aca-europe.eu/index.php/en.

27 Disponível: http://network-presidents.eu/.

28 Disponível em: http://ec.europa.eu/justice/events/judicial-training-2013/index_en.htm.

29 Workshop on the training of legal practitioners - Teaching EU law and judgecraft/Brussels, 28 November 2013, SPEECH/13/994, disponível em: http://europa.eu/rapid/press-release_ SPEECH-13-994_en.htm.

30 O presente estudo surge como resultado de convite lançado, em 2015, pela então Câmara dos Solicitadores portuguesa para temáticas com interesse para esta classe profissional.

31 Comparando-o com a primeira lei escrita de direito romano, a Lei das Doze Tábuas, do século V a.C., que influenciou uma boa parte dos direitos dos Estados-Membros atuais da UE.

32 CAMPOS, João Mota de; CAMPOS, João Luiz; PEREIRA, António Pinto. Manual de Direito Europeu. 2014, p. 295.

33 Por oposição a direito subjetivo, faculdade ou poder de agir de determinada maneira, prerrogativa superiormente tutelada (ver GONÇALVES, Maria João. Sumários de Introdução ao Direito e Noções Fundamentais. 1999, p.31).

34 Ver GONÇALVES, Maria João. Sumários de Introdução ao Direito e Noçães Fundamentais. 1999, p. 117, e, também, JUSTO, A. Santos. Introdução ao Estudo do Direito. 2001, p. 183. 
35 Ver GONÇALVES, Maria João. Sumários de Introdução ao Direito e Noções Fundamentais. 1999, p. 118.

36 CAMPOS, João Mota. Organizações Internacionais. 2010, p. 137.

37 GORJÃO-HENRIQUES, Miguel. Direito da União. 2017, p. 277.

38 CAMPOS, João Mota de; CAMPOS, João Luiz; PEREIRA, António Pinto. Manual de Direito Europeu. 2014, p. 295. Os Tratados originários que instituíram as três Comunidades: COMUNIDADE EUROPEIA DO CARVÃO E DO AÇO (C. E. C. A.) Tratado de Paris de 18 de Abril de 1951, que vigorou até 23 de Julho de 2002. - COMUNIDADE (ECONÓMICA) EUROPEIA (C. E.) Tratado de Roma de 25 de Março de 1957. - COMUNIDADE EUROPEIA DA ENERGIA ATÓMICA (C. E. E. A. ou Euratom) Tratado de Roma de 25 de Março de 1957.

39 CAMPOS, João Mota de; CAMPOS, João Luiz; PEREIRA, António Pinto. Manual de Direito Europeu. 2014, p. 298. Os tratados que operaram as revisões aos Tratados das Comunidades Europeias, que vieram rever globalmente os tratados originários:

- Acto Único Europeu em 17 e 28 de Fevereiro de 1986 - entrou em vigor em 1 de Julho de 1987;

- Tratado de Maastricht ou Tratado da União Europeia de 7 de Fevereiro de 1992, entrou em vigor em 1 de Novembro de 1993;

- Tratado de Amsterdão de 2 de Outubro de 1997, entrou em vigor em 1 de Maio de 1999;

- Tratado de Nice de 26 de Fevereiro de 2001, entrou em vigor em 1 de Fevereiro de 2003;

- Tratado de Lisboa de 13 de Dezembro de 2007, entrou em vigor em 1 de Dezembro de 2009.

40 Do direito originário fazem também parte os diversos tratados de adesão, que provocam alterações nos tratados institutivos.

São eles: pelo Tratado de Bruxelas de 22 de Janeiro de 1972, ocorreu o primeiro alargamento de Reino Unido, Dinamarca e Irlanda (concretizado em 01.01.1973); pelo Tratado de Atenas de 28 de Maio de 1979, verificou-se o segundo alargamento da Grécia (concretizado em 01.01.1981); pelo Tratado de Lisboa de 12 de Junho de 1985 e Tratado de Madrid de 12 de Junho de 1985 ocorreu o terceiro Alargamento com Portugal e Espanha (concretizado em 01.01.1886); pelo Tratado de Corfu de 23 de Junho de 1994, ocorreu o quarto alargamento com Áustria, Suécia e Finlândia (concretizado em 01.01.1995); pelo Tratado de Atenas de 16 de Abril de 2003, verificou-se o quinto alargamento: Estónia, Polónia, República Checa, Eslovénia, Hungria, Letónia, Lituânia, Eslováquia, Malta, Chipre (concretizado em 01.05.2004); pelo Tratado do Luxemburgo de 25 de Abril de 2005 ocorreu o sexto alargamento: Roménia, Bulgária (concretizado em 01.01.2007); pelo Tratado de Bruxelas de 9 de Dezembro de 2011 verificou-se o sétimo alargamento: Croácia (concretizado 01.07.2013). Nos termos do atual artigo $49 .^{\circ}$ do TUE.

41 Sem esquecer o artigo $51 .^{\circ}$ do TUE, que eleva a direito originário Protocolos anexos aos tratados (por exemplo mencionados nos artigos $245 .^{\circ}, \mathrm{n} .^{\circ} 1,266 .^{\circ}, \$ 3 .^{\circ}$, e $281 .^{\circ}, \S 1 .^{\circ}$, do TCE), há ainda outros tratados com esse valor constitucional, como, por exemplo:

- a "Convenção relativa a certas Instituições comuns às Comunidades Europeias" de 25 de Março de 1957 (Convenção revogada pelo artigo 9. $.^{\circ}, \mathrm{n} .^{\circ}$ 1, do Tratado de Amesterdão, estabelecendo o n. 2 que as instituições únicas mantêm as competências nos termos de cada tratado);

- o Tratado Merger de 8 de Abril de 1965, acordo que institui a fusão dos órgãos executivos das três Comunidades (Tratado revogado pelo artigo $9 .^{\circ}, \mathrm{n} .{ }^{\circ}$ 1, do Tratado de Amesterdão);

- o Tratado do Luxemburgo de 22 de Abril de 1970 que prevê o financiamento da Comunidade através de recursos próprios, alterando as disposições orçamentais dos Tratados;

- o Tratado de Bruxelas de 22 de Julho de 1975, que reforça os poderes orçamentais do Parlamento Europeu (ver artigos $311 .^{\circ}$ e $314 .^{\circ}$ do TFUE, e institui um Tribunal de Contas (ver artigos $13 .^{\circ}$ do TUE e $285 .^{\circ}$ a $287 .^{\circ}$ do TFUE).

- o Acto de Bruxelas relativo à eleição dos representantes ao Parlamento Europeu por sufrágio universal direto de 20 de Setembro de 1976 (Ver artigos $14 .^{\circ}$ do TUE e 223. ${ }^{\circ}$ do TFUE. Decisão 76/787/CECA, CEE, Euratom de 20.09.1976 (JOCE L 278 de 08.10.1976). Alterada pela Decisão 2002/772/CE, Euratom do Conselho de 25 de Junho e em 23 de Setembro de 2002 (JOCE L 283 de 21.10.2002) e pela Decisão (UE, Euratom) 2018/994 do Conselho de 13 de julho de 2018 (JOUE L 178 de 16.07 .2018 , pp. 1 a 3 ). 
- a Carta dos Direitos Fundamentais (artigo 6. ${ }^{\circ}$ do TUE e republicação do texto em 2007/C 303/01, JOUE C 303 de 14.12.2007).

42 GORJÃO-HENRIQUES, Miguel. Direito da União. 2017, p. 295.

43 Publicação do Regulamento (CE) n. ${ }^{\circ}$ 1/2003 do Conselho de 16 de Dezembro de 2002, relativo à execução das regras de concorrência estabelecidas nos artigos $81 .^{\circ}$ e $82 .^{\circ}$ do Tratado (JOCE L 1 de 04.01.2003) e que revoga o Regulamento n..$^{\circ} 17$ do Conselho de 6 de Fevereiro de 1962, Primeiro Regulamento de execução das regras de concorrência estabelecidas nos artigos $85 .^{\circ}$ e $86 .^{\circ}$ do Tratado (JO 13 de 21.02.1962), que vigorou até 30 de Abril de 2004.

44 Exemplo: Regulamento (CE) n. ${ }^{\circ}$ 622/2008 da Comissão de 30 de Junho de 2008, que altera o Regulamento (CE) n. ${ }^{\circ} 773 / 2004$, no que se refere à condução de procedimentos de transação nos processos de cartéis, sendo o texto relevante no Espaço Económico Europeu, JOUE L 171 de 01.07.2008, pp. 3 a 5.

45 Exemplo: Regulamento (CE) n. ${ }^{\circ} 1335 / 2008$ do Parlamento Europeu e do Conselho de 16 de Dezembro, que altera o Regulamento (CE) n. ${ }^{\circ} 881 / 2004$ do Parlamento Europeu e do Conselho de 29 de Abril (JOUE L 164 de 30.04.2004, p. 1, retificado no JOUE L 220 de 21.06.2004, p. 3) que institui a Agência Ferroviária Europeia (JOUE L 354 de 31.12.2008, pp. 51 a 59).

46 Artigo $132 .{ }^{\circ}$, n. $^{\circ} 1$, do TFUE.

47 CAMPOS, João Mota de; CAMPOS, João Luiz; PEREIRA, António Pinto. Manual de Direito Europeu. 2014, p. 322.

48 Idem, p. 325.

49 CAMPOS, João Mota de; CAMPOS, João Luiz; PEREIRA, António Pinto. Manual de Direito Europeu. 2014, p. 334.

50 GORJÃO-HENRIQUES, Miguel. Direito da União. 2017, p. 326.

51 CAMPOS, João Mota de; CAMPOS, João Luiz; PEREIRA, António Pinto. Manual de Direito Europeu. 2014, p. 342.

52 Por exemplo, dirigidas aos Estados-Membros nos artigos 121. ${ }^{\circ}, \mathrm{n} . .^{\circ} 2, \S 3 .^{\circ}, 126 .^{\circ}$, n. ${ }^{\circ} 4$, do TFUE.

53 Por exemplo, ao Conselho nos artigos 207..$^{\circ}$ n. ${ }^{\circ} 3, \S 2 .^{\circ}$, e 218. ${ }^{\circ}$ n..$^{\circ}$, do TFUE e aos EstadosMembros no artigo 117. ${ }^{\circ}$ do TFUE.

54 Ver a Recomendação do Parlamento Europeu sobre a qualidade da justiça penal e a harmonização da legislação penal nos Estados-Membros no JOUE C 304 E de 01.12.2005, p. 109.

55 Por exemplo, nos artigos $126 .^{\circ}$, n. ${ }^{\circ} 4$, ou $218 .^{\circ}$, n. $^{\circ} 11$ do TFUE.

56 GORJÃO-HENRIQUES, Miguel. Direito da União. 2017, p. 326.

57 ALVES, Dora Resende. “O direito do consumidor através da aplicação do direito da União Europeia”. I Congresso Internacional de Direito do Consumidor Os desafios do mercado digital para os contratos de consumo. Universidade Portucalense, Porto, em 19 de janeiro de 2018.

58 GORJÃO-HENRIQUES, Miguel. Direito da União. 2017, p. 327, e CAMPOS, João Mota de; CAMPOS, João Luiz; PEREIRA, António Pinto. Manual de Direito Europeu. 2014, pp. 340 e 341.

59 DERO-BUGNY, Delphine. «Le livre vert de la Commission». 2005, pp. 81 a 104.

60 CAMPOS, João Mota de; CAMPOS, João Luiz; PEREIRA, António Pinto. Manual de Direito Europeu. 2014, p. 342.

61 Nos artigos $199 .^{\circ}, 240 .^{\circ}$, n. ${ }^{\circ} 3,249 .^{\circ}$, n. $.^{\circ} 1,253 .^{\circ}, \S 6 .^{\circ}, 254 .^{\circ}, \S 5 .^{\circ}$, do TFUE.

62 No artigo $322 .^{\circ}$ do TFUE. 
63 CAMPOS, João Mota de; CAMPOS, João Luiz; PEREIRA, António Pinto. Manual de Direito Europeu. 2014, pp. 341 e 342.

64 Idem, p. 342.

65 Exemplos: Propostas Legislativas adotadas pela Comissão 2004/C 290/05 em JOUE C 290 de 27.11.2004, p. 5.

66 Por exemplo a Decisão do Conselho (UE) 2015/809 de 19 de maio de 2015, que designou as cidades de Plovdiv, na Bulgária, e Matera, na Itália, para Capital Europeia da Cultura para o ano de 2019 (JOUE L 128 de 23.05.2015, p. 20).

67 De diverso tipo, exemplos: publicação de versões consolidadas dos Tratados (2006/C 321 E/01 em JOUE C 321E de 29.12.2006, p. 1); informação relativa à entrada em vigor de um tratado (Comunicação do Conselho 2006/C 321/01 em JOUE C 321 de 29.12.2006, p. 1).

68 Tal como: o Programa da Haia de 2004 (JOUE C 53 de 03.03.2005, p. 1).

69 Exemplo: $\operatorname{artigo} 17 .^{\circ}$, n. ${ }^{\circ} 1$, do TUE.

70 O dos tribunais comunitários, publicado em 2007/C 223/01, JOUE C 223 de 22.09.2007, pp. 1 e 2, Informação oriunda das instituições e órgãos da União Europeia com o Código de Conduta do Tribunal de Justiça, com certas obrigações para os membros do Tribunal de Justiça, do Tribunal de Primeira Instância e do Tribunal da Função Pública. Ou o Código de Conduta da União Europeia relativo à exportação de armas aprovado em 8 de Junho de 1998, ver JOUE C 300 de 22.11.2008, p. 1.

71 Os Livros Verdes são atos não previstos nos Tratados, que resultam da prática da Comissão e se inspiram nos Green Papers do direito inglês desde 1967. Trata-se de um documento de reflexão e consulta elaborado pela Comissão, que intervém em domínios muito diversos onde lhe parece necessária uma reforma, constituindo um instrumento de democratização da União Europeia (DERO-BUGNY, Delphine. «Le livre vert de la Commission européenne», 2005, pp. 81 a 104). Exemplo: Livro Verde apresentado pela Comissão sobre Acções de indemnização devido à violação das regras comunitárias no domínio antitrust, documento COM(2005) 672 final, de 19.12.2005).

72 Os Livros Brancos são documentos que apresentam propostas de ação comunitária num domínio específico, apresentando um pacote oficial de propostas em áreas de atividade específicas contribuindo para o seu desenvolvimento. Muitas vezes surgem na sequência de um Livro Verde, publicado para lançar um processo de consulta a nível europeu, expondo uma série de ideias para análise e debate público (disponível em: http://europa.eu/documents/comm/index_pt.htm).

Exemplos: Livros Brancos da Comissão: Uma estratégia para a revitalização dos caminhos-de-ferro europeus, de 30 de Julho de 1996, documento COM (96) 421 final; A política europeia de transportes no horizonte 2010: a hora das opções, de 12 de Setembro de 2001, documento COM (2001) 0370 final); Livro Branco sobre o futuro da europa - Reflexões e cenários para a UE27 em 2020, documento $\operatorname{COM}(2017) 2025$ final de 1.3.2017.

73 Tais como os dos artigos $15 .^{\circ}$, n. ${ }^{\circ} 6$, alínea d), do TUE e $126 .^{\circ}$, n. ${ }^{\circ} 3, \S 2 .^{\circ}$, do TFUE. Outros exemplos:

- Da atividade do Provedor de Justiça: Relatório anual 2017 2018/C 429/03, JOUE C 429 de 28.11.2018, p. 3, ou o Relatório especial 2018/C 429/04 ao Parlamento Europeu.

- Relatório sobre o acesso à legislação, 2015/C 97/03, JOUE C 97 de 24.03.2015, pp. 2 a 10.

74 Para os tribunais comunitários. Exemplo publicado no JOUE L 31 de 31.01.2014, pp. 1 a 13, documento "Instruções práticas às partes relativas aos processos apresentados no Tribunal de Justiça”.

$75 \mathrm{Ou}$ acordos celebrados entre as instituições da UE, tão antigos como as instituições europeias têm agora base jurídica própria nos termos do artigo 295. ${ }^{\circ}$ do TFUE (Ver Acordo Interinstitucional entre o Provedor de Justiça Europeu e o Banco Europeu de Investimento 2008/C 244/01 relativo às informações sobre as políticas, as regras e os procedimentos do Banco, assim como ao tratamento das queixas, incluindo as de iniciativa de cidadãos de países terceiros e de não residentes na União 
Europeia, no JOUE C 244 de 25.09.2008, pp. 1 e 2, ou o Acordo-quadro sobre as relações entre o Parlamento Europeu e a Comissão Europeia no JOUE L 304 de 20.11.2010, pp. 47 a 62.), ou declarações conjuntas, fundamentados desde 2000 na Declaração n. ${ }^{\circ} 3$ anexa ao Tratado de Nice.

76 MARRANA, Rui Miguel. "O acesso à informação no quadro do funcionamento da União Europeia", 2012, p. 11.

77 Por exemplo, no âmbito do direito comunitário da concorrência, ao abrigo do Regulamento (CE) n. ${ }^{\circ}$ 1/2003 do Conselho de 16 de Dezembro de 2002, relativo à execução das regras de concorrência estabelecidas nos artigos $81 .^{\circ}$ e 82. ${ }^{\circ}$ do Tratado (JOCE L 1 de 04.01.2003).

78 Ver listagem em Anexo do Regimento do Parlamento Europeu, na edição de julho de 2019 (https://www.europarl.europa.eu/sipade/rules20190702/Rules20190702_PT.pdf).

79 Como o caso do documento COM Uma agenda para os cidadãos: por uma Europa de resultados - (2006) 211, de 10.05.2006.

80 Exemplos: Orçamento 2008/488/CE, Euratom do Parlamento Europeu publicado no JOUE L 175 de 04.07.2008, p. 1.

81 De diverso tipo, por exemplo:

- Informação oriunda das instituições e dos órgãos da União Europeia 2007/C 303/01 com a republicação do texto da Carta dos Direitos Fundamentais da União Europeia proclamada em 7 de Dezembro de 2000, texto esse adaptado e válido a partir da entrada em vigor do Tratado de Lisboa (JOUE C 303 de 14.12.2007, pp. 1 a 16);

- do Parlamento Europeu 2008/C 275 E/01, com a Acta da reunião de 1 de Setembro de 2008 em JOUE C 275 de 30.10.2008, p. 1;

- Nota informativa do Tribunal de Justiça 2005/C 143/01 relativa à apresentação de pedidos de decisão prejudicial pelos órgãos jurisdicionais nacionais (JOUE C 143 de 11.06.2005, pp. 1 a 4). Apenas como exemplo, atento que esta matéria vem hoje em documento mais recente, nas Recomendações 2018/C 257/01 à atenção dos órgãos jurisdicionais nacionais, relativas à apresentação de processos prejudiciais (JOUE C 257 de 20.07.2018, pp. 1 a 8).

82 Exemplo: Convite do Parlamento Europeu à apresentação de candidaturas, tendo em vista a nomeação do Provedor de Justiça Europeu (2009/C 216/06) no JOUE C 216 de 10.09.2009, pp. 7 e 8.

83 Artigo revogado pelo Tratado de Lisboa. Ver PORTO, Manuel Lopes e ANASTÁCIO, Gonçalo. Tratado de Lisboa. 2012.

84 Exemplo: Decisão da Conferência dos Representantes dos Governos dos Estados-Membros da União Europeia 2007/368/CE, Euratom de 23 de Maio de 2007 relativa à nomeação de um juiz do Tribunal de Primeira Instância das Comunidades Europeias (JOUE L 139 de 31.05.2007).

85 GORJÃO-HENRIQUES, Miguel. Direito da União. 2017, p. 329.

86 CAMPOS, João Mota de; CAMPOS, João Luiz; PEREIRA, António Pinto. Manual de Direito Europeu. 2014, p. 305.

87 Ver também nas Declarações relativas a disposições dos Tratados, a Declaração 24 sobre a personalidade jurídica da União Europeia anexa ao Tratado de Lisboa.

88 CAMPOS, João Mota de; CAMPOS, João Luiz; PEREIRA, António Pinto. Manual de Direito Europeu. 2014, p. 238.

89 Desde jurisprudência do TJCE de 1982. Ver MOREIRA, Vital. "A “cláusula de direitos humanos" nos acordos internacionais da União Europeia”, 2014, p. 418.

90 Mais recentemente, coloca-se a nova questão de celebração pela União Europeia de acordo com outras organizações internacionais. Nomeadamente, na sequência das alterações introduzidas pelo Tratado de Lisboa, o qual veio consagrar expressamente, no artigo $6 .^{\circ}, \mathrm{n} .^{\circ} 2$, TUE, que a UE aderirá à $\mathrm{CEDH}$, de forma a suprir a falta de competência da UE apontada pelo mesmo Tribunal, 
aquando da primeira tentativa de adesão (Parecer 2/94 do Tribunal de Justiça de 28.03.1996, ao abrigo da competência consultiva do hoje artigo $218 .^{\circ}$, n. $^{\circ} 11$, do TFUE. Novo Parecer sobre o tema, nomeadamente o Parecer 2/13 de 18 de Dezembro de 2014 do Tribunal de Justiça. Este parecer surge na sequência das alterações introduzidas pelo Tratado de Lisboa, representando um culminar de vários anos de negociações entre a Comissão e o Conselho da Europa. O referido parecer deu, de novo, apreciação negativa ao Acordo relativo à adesão da União Europeia à Convenção Europeia dos Direitos do Homem, embora por razões diversas. Ver ENES, Graça, "O Parecer 2/13 do Tribunal de Justiça...”, 2017.

91 Como exemplo, no Diário da República, $1 .^{\text {a }}$ série, n. ${ }^{\circ} 127$ de 3 de julho de 2012, pp. 3379 a 3386, o Decreto do Presidente da República n. 99/2012 e a Resolução da Assembleia da República n. ${ }^{\circ}$ 84/2012 para ratificação do Tratado sobre Estabilidade, Coordenação e Governação na União Económica e Monetária, assinado em Bruxelas em 2 de março de 2012, cujo texto é publicado em anexo. A entrada em vigor do Tratado foi em 1 de Janeiro de 2013.

92 CAMPOS, João Mota de; CAMPOS, João Luiz; PEREIRA, António Pinto. Manual de Direito Europeu. 2014, p. 341.

93 Os acórdãos são publicados em Coletâneas de Jurisprudência e constam também de menção resumida e periódica no Jornal Oficial de que é exemplo o JOUE C 319 de 23.09.2019, entre muitos que se encontram sob o título Informações oriundas das instituições e dos órgãos da União Europeia. MARTINS, Ana Maria Guerra. Manual de Direito da União Europeia. 2017, p. 509.

94 Ver, das autoras, "A noção de jurisdição para efeitos de interpelação de recurso prejudicial: a questão dos tribunais arbitrais", 2015.

95 Sempre que surja uma questão sobre a interpretação dos Tratados durante um processo a decorrer num tribunal de qualquer Estado-Membro, esse tribunal pode pedir ao Tribunal de Justiça que se pronuncie sobre essa interpretação, porque, embora os tribunais nacionais sejam tribunais comuns de aplicação do direito comunitário, o Tribunal de Justiça da União Europeia é que tem o monopólio da interpretação do mesmo e através deste instrumento de colaboração vai proceder à interpretação uniforme e, por via disso, à aplicação, também uniforme, do direito comunitário. Sendo assim, o reenvio prejudicial tem um papel fundamental na salvaguarda da unidade do direito comunitário e tem sido através dele que se tem pronunciado de forma criadora sobre a natureza jurídica das disposições comunitárias, tendo, nomeadamente, por este meio, criado os princípios, hoje fundamentais, do primado e da aplicabilidade direta do direito comunitário, entre muitos outros conceitos concretos como, por exemplo, no âmbito de aplicação do direito comunitário da concorrência. De acordo com o artigo $267 .^{\circ}$, alíneas a) e b), do TFUE, o recurso tanto pode destinarse a interpretar disposições comunitárias, como apreciar a validade dos atos das instituições comunitárias. Este reenvio é possível em qualquer processo nacional, seja qual for a sua natureza.

96 Apenas no ano de 2018, houve 760 processos findos no Tribunal de Justiça e 1009 no Tribunal Geral. Estatística no TRIBUNAL DE JUSTIÇA. Relatório Anual 2018. 2019.

97 O Tribunal de Justiça da União vem nos artigos $13 .^{\circ}$, n..$^{\circ}$, e $19 .^{\circ}$ do TUE e nos artigos $251 .^{\circ}$ a 257..$^{\circ}$ TFUE, artigos que antecedem as previsões sobre o contencioso comunitário. É constituído por juízes e advogados-gerais.

98 O Tribunal de Primeira Instância das Comunidades Europeias não figurava na versão originária dos Tratados das Comunidades. Hoje vem enunciado nos artigos $220 .^{\circ}$ e $224 .^{\circ}$ a $225 .^{\circ}$-A TCE. Foi criado pela Decisão que institui o Tribunal de Primeira Instância das Comunidades Europeias, Decisão sui generis do Conselho 88/591/CECA, CEE, Euratom de 24 de Outubro de 1988 (JOCE L 319 de 25.11 .1988 , pp. 1 a 8, retificada pelo JOCE L 241 de 17.08.1989, p.4). Revogada pelo artigo 10. ${ }^{\circ}$ do Tratado de Nice de 2001.

99 O Tribunal da Função Pública da União Europeia surgiu pela Decisão do Conselho 2004/752/CE, Euratom de 2 de Novembro de 2004, foi criado tendo em conta a previsão dos artigos 225. ${ }^{\circ}$-A e $245 .^{\circ}$ do TCE e a Declaração n. ${ }^{\circ} 16$ anexa ao Tratado de Nice. Foi um órgão jurisdicional específico para o 
contencioso da função pública, fazendo parte integrante da instituição Tribunal de Justiça (JOUE L 333 de 09.11.2004, pp. 7 a 11). E extinto pelo Regulamento (UE, Euratom) 2016/1192 do Parlamento Europeu e do Conselho de 6 de julho de 2016 (JOUE L 200 de 26.07.2016, pp. 137 a 139) relativo à transferência para o Tribunal Geral da União Europeia da competência para decidir, em primeira instância, dos litígios entre a União Europeia e os seus agentes, com a consequência da extinção do Tribunal da Função Pública. Este Regulamento foi aplicável a partir de 1 de setembro de 2016.

100 Ver ALVES, Dora Resende. "O desempenho do extinto Tribunal da Função Pública da União Europeia e a defesa dos direitos”, 2016.

101 GORJÃO-HENRIQUES, Miguel. Direito da União. 2017, p. 330 e MARTINS, Ana Maria Guerra. Manual de Direito da União Europeia. 2017, p. 511. Um exemplo de aplicação do costume comunitário encontrava-se no modo de funcionamento das reuniões do Conselho Europeu (até ao Conselho Europeu de Londres em 29 e 30 de Junho de 1977, com a adoção da Declaração de Londres, que codifica costumes de carácter processual sobre as reuniões do Conselho Europeu, essas reuniões decorriam de acordo com costumes. Com o Tratado de Lisboa passou a ser uma das instituições (artigo 13. ${ }^{\circ}$ n. ${ }^{\circ}$, do TUE) e dotada de Regulamento Interno de 1 de Dezembro de 2009, 2009/882/UE, no JOUE L 315 de 02.12.2009, pp. 51 a 55).

102 Consulta em http://solicitador.net/pt/pag/OSAE/resumo-historico/1/1/1/88

103 Ver em https://e-justice.europa.eu/content_legal_professions-29-pt-pt.do\#n05

104 Em http://solicitador.net/pt/pag/OSAE/Estatuto/1/1/1/484

105 Disponível em https://www.verbojuridico.net/forense/solicitadores/postulantes.html .

106 De acordo com o preâmbulo da Carta Deontológica dos Postulantes Europeus.

107 Em https://www.uihj.com/.

108 Estabelecidos no artigo $1 .^{\circ}$ da Lei n. ${ }^{\circ}$ 49/2004, de 24 de Agosto que define o sentido e o alcance dos actos próprios dos advogados e dos solicitadores e tipifica o crime de procuradoria ilícita (Sétima alteração ao Estatuto da Ordem dos Advogados e primeira alteração ao Estatuto da Câmara dos Solicitadores), em http://www.pgdlisboa.pt/leis/lei_mostra_articulado.php?nid=84\&ta bela=leis\&nversao=\&so_miolo=, acedido em 26 de setembro de 2019.

109 Em http://www.pgdlisboa.pt/leis/lei_mostra_articulado.php?nid=1959\&tabela=leis\&ficha=1\& pagina $=1 \&$ so_miolo= , acedido em 26 de setembro de 2019.

110 As disposições comunitárias têm uma aptidão para produzir efeitos jurídicos na esfera jurídica dos particulares (pessoas coletivas ou singulares), criando-lhes direitos ou obrigações. Assim sendo, as normas comunitárias têm efeito direto, na medida em que, podem ser invocadas na ordem interna, perante os tribunais nacionais, outros particulares e autoridades administrativas.

111 Artigo 19. ${ }^{\circ}$, n. ${ }^{\circ} 1, \S 2$, do TUE. Ver ABREU, Joana Covelo de. "Tribunais nacionais e tutela jurisdicional efetiva: da cooperação à integração judiciária no Contencioso da União Europeia”. Tese de doutoramento, 2015.

112 Hoje facilmente acessível em http://eur-lex.europa.eu/homepage.html. Este acesso virtual assume especial relevância pelo facto de, a partir de 1 Julho de 2013, apenas a edição eletrónica do Jornal Oficial faz fé e produz efeitos jurídicos, nos termos do Regulamento (UE) n. ${ }^{\circ}$ 216/2013 do Conselho, relativo à publicação eletrónica do Jornal Oficial da União Europeia (JOUE), que determina que o Jornal oficial é publicado sob forma eletrónica, nas 24 línguas oficiais das instituições da União Europeia (JOUE 69 de 13.03.2013, pp.1 a 3).

Desde o Regulamento n. ${ }^{\circ}$, se estabelece o regime linguístico da Comunidade Económica Europeia, no JOUE 17, de 06.10.1958, pp. 385 e 386, retificado no JOUE 34, de 29.05.1959, p. 630. Alterações a este Regulamento pelos: Regulamento (CE) n. ${ }^{\circ}$ 920/2005, do Conselho de 13 de Junho de 2005, em que fixa já em 21 línguas oficiais e de trabalho (JOUE L 156 de 18.06.2005, pp. 3 e 4) e Regulamento (CE) n. ${ }^{\circ}$ 1791/2006 do Conselho de 20 de Novembro de 2006, JOUE L 363 de 20.12.2006). 
113 Ver ALVES, Dora Resende e CLARO, Helder Elias. "Perspectiva sobre a formação judiciária na União Europeia", 2016.

114 Regulamento (CE) n. ${ }^{\circ} 743 / 2002$ do Conselho de 25 de Abril de 2002, já citado.

\section{REFERÊNCIAS}

ABREU, Joana Covelo de. "Tribunais nacionais e tutela jurisdicional efetiva: da cooperação à integração judiciária no Contencioso da União Europeia”. Tese de doutoramento, Universidade do Minho, 2015. Em http://repositorium.sdum.uminho. pt/handle/1822/38880, consulta em 21/03/2019, e Editora Almedina, 2019. ISBN: 9789724078151

ALVES, Dora Resende. Cronologia da Construção Europeia Comunitária. Universidade Portucalense, 2019, apontamentos policopiados.

ALVES, Dora Resende. “O direito do consumidor através da aplicação do direito da União Europeia. Atas do I Congresso Internacional de Direito do Consumidor Os desafios do mercado digital para os contratos de consumo. Universidade Portucalense, Porto, em 19 de janeiro de 2018 (em fase de publicação)

ALVES, Dora Resende e AGUIAR, Ana Raquel. "A diversidade linguística na União Europeia" in María de la Paz Pando Ballesteros, Pedro Garrido Rodríguez, Alicia Muñoz Ramírez (Eds.): El cincuentenario de los Pactos Internacionales de Derechos Humanos de la ONU. Homenaje a la Profesora $M^{a}$. Esther Martínez Quinteiro. Salamanca: Ediciones Universidad de Salamanca, 2018, pp. 233-246. URI: http://hdl.handle.net/11328/2486

ALVES, Dora Resende e CLARO, Helder Elias. "Perspectiva sobre a formação judiciária na União Europeia”, Revista Julgar Online (http://julgar.pt/). Junho de 2016, pp. 1 a 22.

ALVES, Dora Resende. "O desempenho do extinto Tribunal da Função Pública da União Europeia e a defesa dos direitos”, Cadernos de Dereito Actual, N. ${ }^{\circ} 4$. Santiago de Compostela, Espanha, 2016, pp. 185-194. ISSN 2340-860X. Em http://www. cadernosdedereitoactual.es/ojs/index.php/cadernos/article/view/113

ALVES, Dora Resende e BENTO, Márcia Costa. "A noção de jurisdição para efeitos de interpelação de recurso prejudicial: a questão dos tribunais arbitrais", Revista Jurídica Portucalense, $\mathrm{n}^{\circ}$ 17, tomo I, 2015, pp. 89-118. ISSN 0874-2839. URI: http://hdl.handle. net/11328/1115

ALVES, Dora Resende. "Notas sobre o Tratado de Lisboa de 13 de Dezembro de 2007". Revista Jurídica. No 13: (2008). Universidade Portucalense, pp. 27 a 40. ISNN 0874-2839.

BORCHARDT, Klaus-Dieter. ABC do Direito Comunitário. Comissão Europeia. Luxemburgo: Serviço das Publicações da União Europeia, 2017. ISBN 978-92-79-636493 doi:10.2775/68838. Em http://publications.europa.eu/resource/cellar/5d4f8cde-de2511e7-a506-01aa75ed71a1.0015.01/DOC_1 
CAMPOS, João Mota de; CAMPOS, João Luiz; PEREIRA, António Pinto. Manual de Direito Europeu - O sistema institucional a ordem jurídica e o ordenamento económico da União Europeia. Coimbra: Coimbra- Editora. 7. a ed., 2014. ISBN 978-972-32-2209-8.

CAMPOS, João Mota de (coordenação). Organizações Internacionais. Coimbra: Wolters Kluwer | Coimbra Editora. 4. ${ }^{\text {a }}$ ed., 2010.

DERO-BUGNY, Delphine. "Le livre vert" de la Commission européenne in Revue trimestrielle de droit européen. 41, n. ${ }^{\circ}$ 1, janv.-mars 2005. Paris: Dalloz. ISBN 0035-4317.

ENES, Graça. "O Parecer 2/13 do Tribunal de Justiça: Primado do Direito v. Primado dos Direitos", in IX Encontro de Professores de Direito Público, Ana Gouveia Martins, Anabela Leão, Benedita Mac Crorie, Patrícia Fragoso Martins (org), Universidade Católica Editora, Lisboa, 2017A, pp. 68-116.

GONÇALVES, Maria João. Sumários de Introdução ao Direito e Noções Fundamentais. Universidade Portucalense,1999, apontamentos policopiados.

GORJÃO-HENRIQUES, Miguel. Direito da União - História, Direito, Cidadania, Mercado Interno e Concorrência. Coimbra: Livraria Almedina. 9. a ed., 2019. ISBN 978972-40-7658-4. (citada a 8. a edição de 2017)

GORJÃO-HENRIQUES, Miguel. Tratado de Lisboa. 7. ed. Coimbra: Livraria Almedina, reimpressão 2018. ISBN 978-972-40-6835-0.

JUSTO, A. Santos. Introdução ao Estudo do Direito. Coimbra Editora, 2001. ISBN $972-$ 32-1210-2.

MARRANA, Rui Miguel. "O acesso à informação no quadro do funcionamento da União Europeia” in Revista de Ciências Empresariais e Jurídicas. Instituto Superior de Contabilidade e Administração do Porto, n. ${ }^{\circ} 21,2012$. ISSN 1646-1029.

MARTINS, Ana Maria Guerra. Manual de Direito da União Europeia. 2. a ed. Coimbra: Almedina Editora, 2017. ISBN 978-972-40-69-29-6.

MOREIRA, Vital. “A "cláusula de direitos humanos" nos acordos internacionais da União Europeia" in Para Jorge Leite. II Volume. Coimbra Editora, 2014, p. 418. ISBN 978-972-32-2260-9.

PORTO, Manuel Lopes e ANASTÁCIO, Gonçalo (coordenação). Tratado de Lisboa anotado e comentado. Almedina, 2012. ISBN 978-972-40-4613-6.

TRIBUNAL DE JUSTIÇA. Relatório Anual 2018 Panorama do ano. Luxemburgo: Serviço das Publicações da União Europeia, 2019. ISBN 978-92-829-2987-2. Em https://curia. europa.eu/jcms/upload/docs/application/pdf/2019-06/20190650_ra_pan_pt_2019-0606_09-48-22_369.pdf consulta em 23.09.2019. 


\title{
A FORMAÇÃO JUDICIÁRIA NA UNIÃO EUROPEIA E OS SOLICITADORES
}

\begin{abstract}
Resumo
A criação de um espaço judiciário europeu, dada a diversidade de sistemas jurídicos e judiciários dos respetivos Estados-Membros reclama uma formação judiciária adequada para os profissionais forenses. A formação judiciária dos solicitadores é indispensável à salvaguarda da aplicação correta e uniforme do direito a União Europeia e, dessa forma, funciona como uma garantia da proteção dos direitos dos particulares.

Palavras-chave: Solicitador. Formação judiciária. União Europeia. direito da União Europeia.
\end{abstract}




\title{
JUDICIAL TRAINING IN THE EUROPEAN UNION AND SOLICITORS
}

\begin{abstract}
The creation of a European judicial area, given the diversity of legal and judicial systems of the respective member states, calls for a proper judicial training to legal professionals. Judicial training to solicitors is essential to safeguard the correct and uniform enforcement of European Union law and also acts as a guarantee of protection of individual rights.
\end{abstract}

Keywords: Solicitor. Judicial Training. European Union. European law. 